\title{
Imaging Parameters of the Ipsilateral Medial Geniculate Body May Predict Prognosis of Patients with Idiopathic Unilateral Sudden Sensorineural Hearing Loss on the Basis of Diffusion Spectrum Imaging
}

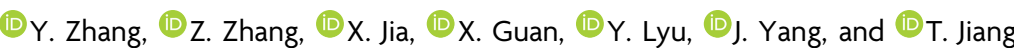

\begin{abstract}
BACKGROUND AND PURPOSE: Idiopathic sudden sensorineural hearing loss is an acute unexplained onset of hearing loss. We examined the central auditory pathway abnormalities in patients with unilateral idiopathic sudden sensorineural hearing loss using diffusion spectrum imaging and the relationships between hearing recovery and diffusion spectrum imaging parameters.

MATERIALS AND METHODS: Forty-eight patients with unilateral idiopathic sudden sensorineural hearing loss with a duration of $\leq 2$ weeks (range, $8.9 \pm 4.3$ days) and 20 healthy subjects underwent diffusion spectrum imaging tractography. Hearing levels were evaluated using a pure-tone average at initial presentation and 3-month follow-up. Clinical characteristics and MR imaging findings were assessed.

RESULTS: Compared with healthy control subjects, the generalized fractional anisotropy values of patients decreased significantly in the bilateral posterior limbs of the internal capsule, with no differences between the ipsilateral and contralateral sides. The quantitative anisotropy values decreased in the Brodmann area 41, contralateral medial geniculate body, bilateral lateral lemniscus, anterior limb of internal capsule, middle temporal gyrus, and anterior corona radiata. Furthermore, at 3-month follow-up, 14 patients had $<15 \mathrm{~dB}$ of hearing gain. Receiver operating characteristic curve analysis demonstrated that generalized fractional anisotropy in the ipsilateral medial geniculate body was related to prognosis (sensitivity $=64.7 \%$; specificity $=85.7 \%$; area under the curve $=0.796,95 \% \mathrm{Cl}, 0.661-0.931 ; P<.01)$.
\end{abstract}

CONCLUSIONS: Diffusion spectrum imaging can detect abnormalities of white matter microstructure along the central auditory pathway in patients with unilateral idiopathic sudden sensorineural hearing loss. The generalized fractional anisotropy value of the ipsilateral medial geniculate body may help to predict recovery outcomes.

ABBREVIATIONS: DSI = diffusion spectrum imaging; FA = fractional anisotropy; GFA = generalized fractional anisotropy; ISSHL = idiopathic sudden sensorineural hearing loss; $M G B=$ medial geniculate body; $Q A=$ quantitative anisotropy

$\mathrm{H}$ earing plays a crucial role in communication with the outside world. Idiopathic sudden sensorineural hearing loss (ISSHL) is an acute unexplained onset of hearing loss from a cochlear or retrocochlear origin. ${ }^{1,2}$ Sudden sensorineural hearing loss affects approximately 5-27 per 100,000 people

Received March 30, 2020; accepted after revision August 29.

From the Departments of Hyperbaric Oxygen (Y.Z., J.Y.) and Radiology (Z.Z., X.J., Y.L., T.J.), Beijing Chaoyang Hospital, and Department of Radiology (X.G.), Beijing Shijitan Hospital, Capital Medical University, Beijing, China.

Y. Zhang and Z. Zhang are joint first authors.

This study was funded by Beijing Science and Technology Program (Z161100000116067).

Please address correspondence to Jing Yang, MD, Beijing Chaoyang Hospital, 8 Gongren Tiyuchang Nanlu, Chaoyang District, Beijing, CN 100020; e-mail: BJCYlhospitalHBO@126.com

- Indicates open access to non-subscribers at www.ajnr.org

Indicates article with supplemental online table.

http://dx.doi.org/10.3174/ajnr.A6874 annually, and the incidence has increased across recent decades. ${ }^{3,4}$ Viral infections, cochlear ischemia, autoimmune processes, and metabolic derangement have been proposed as potential etiologies. Treatment options include steroids and other medications, hyperbaric oxygen therapy, and other complementary and alternative treatments. However, selection of treatments may be difficult due to the variety of possible etiologies. $^{2}$ Additionally, the hearing prognosis in individual cases is quite uncertain.

High-resolution MR imaging can detect the pathologic changes in the inner ear and the cochlea, providing new insights into the etiology of ISSHL. ${ }^{5}$ A number of studies have examined the prognostic value of white matter abnormalities in hearing loss using T2WI or FLAIR sequences with conflicting results. ${ }^{6,7}$ White matter microstructural changes along the auditory pathway have not been wellevaluated, but DTI is becoming a method to study the central auditory pathways. ${ }^{8,9}$ DTI is sensitive to the highly directional structure 
of white matter, which can reflect the structural or functional changes of white matter. Fractional anisotropy (FA), as a DTI parameter, is considered a marker of fiber tract integrity. On the basis of a recent systematic review, white matter changes can be detected by DTI in patients with sensorineural hearing loss. ${ }^{10}$ However, DTI needs larger sample sizes for standardization, and the spatial resolution limits the further use of DTI in the auditory pathway. By contrast, diffusion spectrum imaging (DSI) generalizes DTI by acquiring more directions in $q$-space, either by high-angular-resolution diffusion imaging shells, a cube on a Cartesian grid, or Q-ball imaging. ${ }^{11}$ Also compared with DTI, DSI can provide a better estimate of areas of crossing or kissing fibers, demyelination, and axonal remodeling. ${ }^{12}$

The aim of the present study was to investigate the value of DSI in detecting microstructural abnormalities of the central auditory pathway in patients with ISSHL and to assess the correlations between clinical outcomes and DSI parameters.

\section{MATERIALS AND METHODS \\ Subjects}

The study included 48 patients with unilateral ISSHL. The duration was $\leq 2$ weeks with mild-to-profound hearing loss. All subjects were inpatients between January 2018 and October 2019 and were diagnosed by an otolaryngologist. The inclusion criteria were as follows: the presence of an unexplained unilateral sensorineural hearing loss of $\geq 30 \mathrm{~dB}$ in at least 3 contiguous audiometric frequencies that developed within 3 days. The exclusion criteria were as follows: 1) a history of Ménière disease, otitis media, or cholesteatoma; 2) history of cerebral infarction; 3) existing anatomic abnormality of the inner ear and auditory pathway; 4) previous otologic surgery; 5) systemic ototoxic drug therapy; 6) images with motion artifacts or patients who cannot tolerate MR imaging; and 7) failure to obtain a 3-month follow-up. As healthy controls, 20 subjects with normal hearing (10 women, 10 men) without a history of neurologic disorders were recruited. This clinical study was approved by the ethics committee of Beijing Chaoyang Hospital, Capital Medical University (assurance No. 2016-88). Written informed consent was obtained before the examination.

\section{Clinical Characteristics and Audiologic Evaluation}

The demographic data and medical history of patients were collected. Pure-tone audiometry was evaluated at initial presentation and at 3-month follow-up. The pure-tone average was calculated as the average at 250, 500, 1000, 2000, 4000, and $8000 \mathrm{~Hz}$. The severity of hearing loss was graded by the pure-tone average as follows: mild $(\leq 40 \mathrm{~dB})$, moderate $(41-70 \mathrm{~dB})$, severe $(71-90 \mathrm{~dB})$, or profound ( $\geq 91 \mathrm{~dB}$ ) hearing loss. The audiogram shapes were classified into 4 subtypes: low-frequency type, high-frequency type, flat type, and profound type. ${ }^{13}$

Hearing recovery was classified according to the Siegel criteria, as follows: ${ }^{1}$ ) healing: final hearing level of $\leq 25 \mathrm{~dB}$; 2) partial recovery: hearing gain of $\geq 15 \mathrm{~dB}$ and final hearing level of 25$45 \mathrm{~dB}$; 3) slight recovery: hearing gain of $\geq 15 \mathrm{~dB}$ and final hearing level of $\geq 45 \mathrm{~dB}$; and 4 ) no response: hearing gain of $<15 \mathrm{~dB}$ or a final hearing threshold of $>75 \mathrm{~dB}$. Healing, partial, and slight recoveries were considered improvement.

\section{Treatment Process}

All patients with ISSHL were treated with the same protocol. Systemic steroid therapy was administered to each patient, involving $1 \mathrm{mg} / \mathrm{kg} /$ day (maximum, $60 \mathrm{mg}$ ) of oral prednisolone for the first 5-6 days. ${ }^{13}$ Hyperbaric oxygen therapy was initiated within 14 days of onset and applied at a pressure of $2.0 \mathrm{~atm}$ for 60 minutes once daily. The use of other medicine was in accordance with the guidelines of the Chinese Medical Association of Otorhinolaryngology, Head and Neck Surgery. ${ }^{13}$

\section{Image Acquisition and Processing}

MR imaging was performed with a 3T Magnetom Prisma scanner (Siemens) using a 64-channel head coil. For structural MR imaging scans for anatomic reference, high-resolution anatomic MR imaging was performed using T1W1 with a rapid-acquisition gradient-echo. The details of the scan parameters are as follows: $\mathrm{TE}=2.27 \mathrm{~ms}$, $\mathrm{TR}=2300 \mathrm{~ms}$, flip angle $=8^{\circ}$, layer number $=208$, voxel $=$ $1.0 \times 1.0 \times 1.0 \mathrm{~mm}$, and FOV $=256 \times 256 \mathrm{~mm}$. DSI data were collected using a twice-refocused spin-echo EPI sequence and multiple $q$-values $(\mathrm{TE}=79 \mathrm{~ms}, \mathrm{TR}=7200 \mathrm{~ms}, \mathrm{FOV}=220 \times 220 \mathrm{~mm}$, voxel size $=2.2 \times 2.2 \times 2.2 \mathrm{~mm}^{3}, \mathrm{~b}$ maximum $=3000 \mathrm{~s} / \mathrm{mm}^{2}$, and 257 directions for a scan time of 15 minutes) as previously described. ${ }^{14}$ For DSI data reconstruction, the study used a generalized $q$-sampling imaging reconstruction of the orientation distribution functions (discrete sampling direction $=362$, average diffusion distance $=1.2 \mathrm{~mm}$ ) as previously reported. ${ }^{11}$ The space-normalization method was used in the CSF calibration to determine the location of CSF and to unify the diffusion amount relative to CSF as free-water diffusion.

Fiber tracking was conducted using DSIStudio (Johns Hopkins University). ROIs were selected in the auditory neural pathway, including the superior olivary nucleus, inferior colliculus, lateral lemniscus, medial geniculate bodies (MGB), anterior limb of the internal capsule, posterior limb of the internal capsule, Heschl gyrus, superior temporal gyrus, middle temporal and inferior temporal gyri, anterior corona radiata, posterior corona radiata, auditory radiation, and Brodmann areas 41 and 42 . Fiber tractography was performed in multifiber orientations (step size in each orientation $=1.0 \mathrm{~mm}$, minimum fiber length $=20 \mathrm{~mm}$, turningangle threshold $=60^{\circ}$ ), as reported..$^{15}$ The same method was adopted to determine the next moving direction if multiple fiber orientations existed, which involved the fiber orientation nearest to the incoming direction and a turning angle of $<60^{\circ}$. The next moving directional estimate of each voxel was weighted by $20 \%$ of the previous incoming direction and $80 \%$ of the nearest fiber orientation, to smooth the tracks. This process was repeated until the quantified anisotropy (QA) of the fiber orientation was below the preset threshold (range, $0.13-0.17$ depending on controls) or no fiber extended in the $60^{\circ}$-angle range. The image was standardized to match and correct the diffusion image in the Montreal Neurological Institute anatomic template. ${ }^{16}$ An optical fibertracking algorithm based on Streamline Tracking Technique (https://www.mathworks.com/matlabcentral/fileexchange/34008-dtifiber-tractography-streamline-tracking-technique) was then implemented, and the QA and generalized fractional anisotropy (GFA) parameters of each ROI were obtained by DSIStudio software. 
Table 1: Demographic data, medical comorbidities, and audiometric characteristics

\begin{tabular}{|c|c|c|c|c|}
\hline \multirow[b]{2}{*}{ Study Characteristics } & \multirow[b]{2}{*}{$\begin{array}{l}\text { All Patients } \\
(n=48)\end{array}$} & \multicolumn{2}{|c|}{ Outcome } & \multirow[b]{2}{*}{$\begin{array}{c}P \\
\text { Value }\end{array}$} \\
\hline & & $\begin{array}{l}\text { Nonimprovement } \\
\text { Group }(n=14)\end{array}$ & $\begin{array}{l}\text { Improvement } \\
\text { Group }(n=34)\end{array}$ & \\
\hline \multicolumn{5}{|l|}{$\operatorname{Sex}(\%)$} \\
\hline Male & $25(52.1)$ & $7(28.0)$ & $18(72.0)$ & .85 \\
\hline Female & 23 (47.9) & $7(30.4)$ & $16(69.6)$ & \\
\hline \multicolumn{5}{|l|}{ Hypertension (\%) } \\
\hline Yes & $17(35.4)$ & $5(29.4)$ & $12(70.6)$ & .97 \\
\hline No & $31(64.6)$ & $9(29.0)$ & $22(71.0)$ & \\
\hline \multicolumn{5}{|l|}{ Type 2 diabetes (\%) } \\
\hline Yes & $10(20.8)$ & $2(20.0)$ & $8(80.0)$ & .47 \\
\hline No & 38 (79.2) & $12(31.6)$ & $26(68.4)$ & \\
\hline \multicolumn{5}{|l|}{ Hyperlipidemia (\%) } \\
\hline Yes & $15(31.2)$ & $4(26.7)$ & $11(73.3)$ & .79 \\
\hline No & $33(68.8)$ & $10(26.3)$ & $23(69.7)$ & \\
\hline \multicolumn{5}{|l|}{ Affected ear (\%) } \\
\hline Left & $29(60.4)$ & $7(24.1)$ & $22(75.9)$ & .34 \\
\hline Right & $19(39.6)$ & $7(36.8)$ & $12(63.2)$ & \\
\hline Age (mean $\pm S D)(y r)$ & $52.3 \pm 10.8$ & $53.5 \pm 11.7$ & $51.88 \pm 10.5$ & .64 \\
\hline $\begin{array}{l}\text { Duration (mean } \pm \text { SD) } \\
\quad \text { (day) }\end{array}$ & $8.9 \pm 4.3$ & $10.2 \pm 5.0$ & $8.4 \pm 3.9$ & .17 \\
\hline PTA $($ mean $\pm \mathrm{SD})(\mathrm{dB})$ & $64.3 \pm 25.6$ & $59.5 \pm 26.1$ & $75.93 \pm 20.7$ & .10 \\
\hline \multicolumn{5}{|l|}{ Audiogram shape (\%) } \\
\hline Low-frequency & $10(20.8)$ & $1(10.0)$ & $9(90.0)$ & .45 \\
\hline High-frequency & $11(22.9)$ & $4(36.4)$ & $7(63.6)$ & \\
\hline Flat & $14(29.2)$ & $4(28.6)$ & $10(71.4)$ & \\
\hline Profound & $13(27.1)$ & $5(38.5)$ & $8(61.5)$ & \\
\hline \multicolumn{5}{|l|}{$\begin{array}{c}\text { Hearing loss severity } \\
\text { based on PTA (\%) }\end{array}$} \\
\hline Mild (40 dB) & $15(31.3)$ & $1(6.7)$ & $14(93.3)$ & .12 \\
\hline Moderate (41-60 dB) & $6(12.5)$ & $3(50.0)$ & $3(50.0)$ & \\
\hline Severe $(61-90 \mathrm{~dB})$ & $18(37.5)$ & $7(38.9)$ & 11 (61.1) & \\
\hline Profound ( $\geq 91 \mathrm{~dB}$ ) & 9 (18.7) & $3(33.3)$ & $6(66.7)$ & \\
\hline
\end{tabular}

Note:-PTA indicates pure-tone average.

\section{Statistical Analysis}

All statistical analyses were performed using statistical software (SPSS, Version 26.0; IBM). Quantitative data are described as mean $\pm \mathrm{SD}$. Categoric data are presented as frequencies. On the basis of data distribution, the Student $t$ test or Mann-Whitney $U$ test was used to compare means between the 2 groups, the paired- $t$ test or Wilcoxon matched-pairs signed rank test was used to compare DSI parameters between both sides in the same subjects, and a 1-way ANOVA or the Kruskal-Wallis rank sum test was used to compare DSI parameters between both sides of patients with those in the healthy control group. Bonferroni correction for multiple testing was applied with a significance level of $P<.05 / N$ ( $N$ equals the number of ROIs). The $\chi^{2}$ test was used to compare categoric data. Receiver operating characteristic curves were plotted; then, the optimum cutoff points of GFA and QA were determined. The area under the curve was used as an estimation of diagnostic accuracy. A value of $P<.05$ was considered statistically significant.

\section{RESULTS}

\section{Demographic and Audiometric Data}

The demographic data, medical comorbidities, and audiometric characteristics are summarized in Table 1 . In total, there were 48 patients with unilateral ISSHL, including 25 (52.1\%) men and 23 (47.9\%) women, with a mean age of $52.3 \pm 10.8$ years (range, $23-68$ years).
The mean duration between the onset of ISSHL and MR imaging was $8.9 \pm$ 4.3 days (range, $1-14$ days). The ISSHL was left-sided in 29 (60.4\%) cases, while there were 19 (39.6\%) right-sided cases. Hypertension (35.4\%) was the most common medical comorbidity, followed by hyperlipidemia (31.2\%) and type 2 diabetes (20.8\%). The mean pure-tone average at onset presentation was $64.3 \pm$ $25.6 \mathrm{~dB}$ (range, 30-110 dB), of which severe hearing loss (37.5\%) was the most common finding, followed by mild (31.3\%), extremely severe (18.7\%), and moderate (12.5\%) hearing loss. The audiogram shape was a low-frequency type in $20.8 \%$ of patients, a high-frequency type in $22.9 \%$, a flat type in $29.2 \%$, and a profound type in $27.1 \%$.

On the basis of the hearing recovery at the end of the 3-month follow-up period, 48 patients were further divided into 2 groups: an improvement group (hearing gain of $\geq 15 \mathrm{~dB}, n=34)$ and nonimprovement group $(<15 \mathrm{~dB}$ of hearing gain, $n=14$ ). However, there were no obvious differences in the above demographic and audiometric characteristics between the groups (Table 1).

\section{Characteristics of DSI Parameter Changes in Unilateral ISSHL}

The DSI parameters (GFA, QA) of 20 healthy, age-matched control subjects (range, 27-60 years of age; mean age, $47.9 \pm 12.5$ years; $P=.089$ ) are shown in Table 2. There were no obvious differences in DSI parameters between the left and right sides of healthy subjects in any of the 13 ROIs. Therefore, a mean value of the left and right sides for each healthy subject in each of the ROIs was used for comparison with patients with unilateral ISSHL.

\section{Differences in DSI Parameters between Patients with Unilateral ISSHL and Healthy Subjects}

The DSI tractography parameters of patients with unilateral ISSHL and healthy subjects, including QA and GFA for each ROI, are shown in Tables 3 and 4.

Compared with the heathy control group, the GFA values of patients with unilateral ISSHL significantly decreased only in the bilateral posterior limb of the internal capsule $(P<.01, P<.05$ after Bonferroni correction). In addition, there was no obvious difference between the ipsilateral and contralateral sides.

The QA values significantly decreased in Brodmann area 41, the contralateral MGB, bilateral lateral lemniscus, anterior limb of the internal capsule, middle temporal gyrus, and anterior corona radiata compared with the healthy control subjects $(P<.01, P<.05$ after Bonferroni correction). Furthermore, obvious differences between the ipsilateral and contralateral sides were found in none of the above sites. 


\section{Differences in QA and GFA between Both Sides of the Same Patient}

This study also compared these DSI parameters between both sides of each patient in the different outcome groups (Online Table). In the nonimprovement group, neither GFA nor QA values were different on either side of each patient. By contrast, in the improvement

Table 2: Characteristics of diffusion spectrum imaging parameters in healthy subjects ${ }^{\mathrm{a}}$

\begin{tabular}{|c|c|c|c|c|}
\hline ROls & Parameters & Left Side & Right Side & $\begin{array}{c}P \\
\text { Value }\end{array}$ \\
\hline \multirow[t]{2}{*}{ Superior olivary nucleus } & QA & $0.6725 \pm 0.0783$ & $0.6584 \pm 0.0910$ & .55 \\
\hline & GFA & $0.0902 \pm 0.0062$ & $0.0896 \pm 0.0081$ & .64 \\
\hline \multirow[t]{2}{*}{ Inferior colliculus } & QA & $0.6531 \pm 0.0800$ & $0.6463 \pm 0.0827$ & .76 \\
\hline & GFA & $0.0936 \pm 0.0052$ & $0.0943 \pm 0.0055$ & .41 \\
\hline \multirow[t]{2}{*}{ Medial geniculate body } & QA & $0.6324 \pm 0.0814$ & $0.6327 \pm 0.0923$ & .98 \\
\hline & GFA & $0.0990 \pm 0.0083$ & $0.0968 \pm 0.0077$ & .26 \\
\hline \multirow[t]{2}{*}{ Lateral lemniscus } & QA & $0.6530 \pm 0.0815$ & $0.6486 \pm 0.0687$ & .83 \\
\hline & GFA & $0.0930 \pm 0.0088$ & $0.0925 \pm 0.0055$ & .76 \\
\hline \multirow{2}{*}{$\begin{array}{l}\text { Anterior limb of internal } \\
\text { capsule }\end{array}$} & QA & $0.5717 \pm 0.0754$ & $0.5871 \pm 0.0754$ & .45 \\
\hline & GFA & $0.0853 \pm 0.0053$ & $0.0877 \pm 0.0044$ & .08 \\
\hline \multirow{2}{*}{$\begin{array}{l}\text { Posterior limb of internal } \\
\text { capsule }\end{array}$} & QA & $0.6947 \pm 0.0635$ & $0.6907 \pm 0.0551$ & .81 \\
\hline & GFA & $0.1046 \pm 0.0035$ & $0.1046 \pm 0.0027$ & .97 \\
\hline \multirow[t]{2}{*}{ Heschl } & QA & $0.6054 \pm 0.0916$ & $0.5792 \pm 0.0763$ & .27 \\
\hline & GFA & $0.0882 \pm 0.0074$ & $0.0831 \pm 0.0141$ & .18 \\
\hline \multirow[t]{2}{*}{ Superior temporal gyrus } & QA & $0.5974 \pm 0.0762$ & $0.5941 \pm 0.0731$ & .87 \\
\hline & GFA & $0.0928 \pm 0.0042$ & $0.0912 \pm 0.0037$ & .09 \\
\hline \multirow[t]{2}{*}{ Middle temporal gyrus } & $\mathrm{QA}$ & $0.6020 \pm 0.0752$ & $0.6064 \pm 0.0720$ & .83 \\
\hline & GFA & $0.0935 \pm 0.0033$ & $0.0929 \pm 0.0029$ & .46 \\
\hline \multirow[t]{2}{*}{ Inferior temporal gyrus } & QA & $0.5594 \pm 0.0661$ & $0.5731 \pm 0.0686$ & .47 \\
\hline & GFA & $0.0849 \pm 0.0079$ & $0.0871 \pm 0.0069$ & .06 \\
\hline \multirow[t]{2}{*}{ Anterior corona radiata } & QA & $0.5868 \pm 0.0717$ & $0.5711 \pm 0.0638$ & .41 \\
\hline & GFA & $0.0951 \pm 0.0044$ & $0.0937 \pm 0.0039$ & .06 \\
\hline \multirow[t]{2}{*}{ Posterior corona radiata } & $\mathrm{QA}$ & $0.7172 \pm 0.0814$ & $0.7081 \pm 0.0785$ & .68 \\
\hline & GFA & $0.1135 \pm 0.0071$ & $0.1126 \pm 0.0077$ & .36 \\
\hline \multirow[t]{2}{*}{ Auditory radiation } & QA & $0.6727 \pm 0.0783$ & $0.6617 \pm 0.0827$ & .62 \\
\hline & GFA & $0.1021 \pm 0.0061$ & $0.1010 \pm 0.0070$ & .49 \\
\hline \multirow{2}{*}{ Brodmann area 41} & QA & \multicolumn{2}{|c|}{$0.6350 \pm 0.0790$} & \\
\hline & GFA & \multicolumn{2}{|c|}{$0.0960 \pm 0.0034$} & \\
\hline \multirow[t]{2}{*}{ Brodmann area 42} & QA & \multicolumn{2}{|c|}{$0.5483 \pm 0.0793$} & \\
\hline & GFA & $0.0831 \pm$ & $=0.0090$ & \\
\hline
\end{tabular}

${ }^{\mathrm{a}}$ Data are mean $\pm \mathrm{SD}$ group, the GFA values of the ipsilateral MGB and lateral lemniscus were significantly higher than the contralateral parameters of the same patient $(P<.05$ after Bonferroni correction).

\section{Prognostic Value of DSI Parameters}

The prognostic values of QA and GFA in the different ROIs are shown in the Online Table. Compared with the nonimprovement group, the GFA value of the ipsilateral MGB was higher in the improvement group $(P<.05$ after Bonferroni correction). The fiber-tracking image of MGB is shown in Fig 1. According to receiver operating characteristic curves, the GFA of the ipsilateral MGB had a cutoff point of 0.0967 based on the Youden Index, an area under the curve of 0.796 (95\% CI, 0.661-0.931; $P=.001$ ), sensitivity of $64.7 \%$, and specificity of $85.7 \%$ (Fig 2).

\section{DISCUSSION}

In humans, the primary acoustic circuit is made up of the auditory nerve, brain stem, thalamus, and auditory cortex. In the cochlea, sound is transduced into a neural signal and then travels via the cochlear nerve to a synapse at the dorsal and ventral cochlear nuclei in the medulla oblongata. Then, the fibers project to the ipsilateral superior olivary nucleus or decussate to the contralateral superior olivary nucleus. Fibers further ascend to the inferior colliculus in the midbrain via the lateral lemniscus and subsequently

Table 3: Differences in GFA between patients with unilateral ISSHL (hearing loss ipsilateral side and contralateral side) and healthy subjects $^{\mathrm{a}}$

\begin{tabular}{|c|c|c|c|c|}
\hline \multirow[b]{2}{*}{ ROls } & \multicolumn{2}{|c|}{ Patients with Unilateral ISSHL } & \multirow[b]{2}{*}{$\begin{array}{l}\text { Healthy Controls } \\
\qquad(n=20)\end{array}$} & \multirow[b]{2}{*}{$\begin{array}{c}P \\
\text { Value }\end{array}$} \\
\hline & $\begin{array}{l}\text { Hearing Loss Ipsilateral Side } \\
\qquad(n=48)\end{array}$ & $\begin{array}{l}\text { Hearing Loss Contralateral Side } \\
\qquad(n=48)\end{array}$ & & \\
\hline Superior olivary nucleus & $0.0898 \pm 0.0142$ & $0.0922 \pm 0.0163$ & $0.08993 \pm 0.0066$ & .69 \\
\hline Inferior colliculus & $0.0951 \pm 0.0090$ & $0.0948 \pm 0.0067$ & $0.0939 \pm 0.0050$ & .84 \\
\hline Medial geniculate body & $0.0963 \pm 0.0116$ & $0.0940 \pm 0.0098$ & $0.0979 \pm 0.0067$ & .31 \\
\hline Lateral lemniscus & $0.0951 \pm 0.0084$ & $0.0911 \pm 0092$ & $0.0928 \pm 0.0061$ & .07 \\
\hline Anterior limb of internal capsule & $0.0816 \pm 0.0068$ & $0.0815 \pm 0.0071$ & $0.0865 \pm 0.0038$ & .01 \\
\hline Posterior limb of internal capsule & $0.0984 \pm 0.0073^{c}$ & $0.0997 \pm 0.0051^{\mathrm{b}}$ & $0.1046 \pm 0.0026$ & .001 \\
\hline Heschl & $0.0829 \pm 0.0228$ & $0.0842 \pm 0.0140$ & $0.0857 \pm 0.0078$ & .83 \\
\hline Superior temporal gyrus & $0.0894 \pm 0.0070$ & $0.0892 \pm 0.0079$ & $0.0920 \pm 0.0034$ & .28 \\
\hline Middle temporal gyrus & $0.0920 \pm 0.0057$ & $0.0907 \pm 0.0061$ & $0.0932 \pm 0.0026$ & .20 \\
\hline Inferior temporal gyrus & $0.0850 \pm 0.0084$ & $0.0850 \pm 0.0071$ & $0.0859 \pm 0.0064$ & .89 \\
\hline Anterior corona radiata & $0.0884 \pm 0.0075$ & $0.0881 \pm 0.0076$ & $0.0941 \pm 0.0039$ & .005 \\
\hline Posterior corona radiata & $0.1084 \pm 0.0093$ & $0.1079 \pm 0.0091$ & $0.1131 \pm 0.0071$ & .08 \\
\hline Auditory radiation & $0.0997 \pm 0.0089$ & $0.0992 \pm 0.0093$ & $0.1015 \pm 0.0057$ & .61 \\
\hline Brodmann area 41 & \multicolumn{2}{|c|}{$0.0950 \pm 0.0074$} & $0.0960 \pm 0.0034$ & .47 \\
\hline Brodmann area 42 & \multicolumn{2}{|c|}{$0.0812 \pm 0.0085$} & $0.0831 \pm 0.0090$ & .41 \\
\hline
\end{tabular}

\footnotetext{
a Data are mean \pm SD.

${ }^{\mathrm{b}}$ Compared with the control group, $P<.05$ after Bonferroni correction.

${ }^{c}$ Compared with the control group, $P<.01$ after Bonferroni correction.
} 
Table 4: Differences in QA between patients with unilateral ISSHL (hearing loss ipsilateral side and contralateral side) and healthy subjects $^{\mathrm{a}}$

\begin{tabular}{|c|c|c|c|c|}
\hline \multirow[b]{2}{*}{ ROIs } & \multicolumn{2}{|c|}{ Patients with Unilateral ISSHL } & \multirow[b]{2}{*}{$\begin{array}{l}\text { Healthy Controls } \\
(n=20)\end{array}$} & \multirow[b]{2}{*}{$\begin{array}{c}P \\
\text { Value }\end{array}$} \\
\hline & $\begin{array}{l}\text { Hearing Loss Ipsilateral Side } \\
\qquad(n=48)\end{array}$ & $\begin{array}{l}\text { Hearing Loss Contralateral Side } \\
\qquad(n=48)\end{array}$ & & \\
\hline Superior olivary nucleus & $0.5883 \pm 0.1047$ & $0.6058 \pm 0.0989$ & $0.6578 \pm 0.0852$ & .04 \\
\hline Inferior colliculus & $0.6006 \pm 0.0844$ & $0.5949 \pm 0.0787$ & $0.6463 \pm 0.0860$ & .06 \\
\hline Medial geniculate body & $0.5607 \pm 0.0949$ & $0.5395 \pm 0.0876^{b}$ & $0.6309 \pm 0.0883$ & .001 \\
\hline Lateral lemniscus & $0.5986 \pm 0.0903^{c}$ & $0.5588 \pm 0.1002^{b}$ & $0.6527 \pm 0.0714$ & .001 \\
\hline Anterior limb of internal capsule & $0.4798 \pm 0.0778^{b}$ & $0.4825 \pm 0.0868^{b}$ & $0.5799 \pm 0.0646$ & $<.001$ \\
\hline Posterior limb of internal capsule & $0.6264 \pm 0.1115$ & $0.6342 \pm 0.0974$ & $0.6895 \pm 0.0585$ & .04 \\
\hline Heschl & $0.4931 \pm 0.1452$ & $0.5029 \pm 0.1011$ & $0.5840 \pm 0.0799$ & .01 \\
\hline Superior temporal gyrus & $0.5249 \pm 0.0812$ & $0.5266 \pm 0.0820$ & $0.5918 \pm 0.0759$ & .005 \\
\hline Middle temporal gyrus & $0.5421 \pm 0.0732^{c}$ & $0.5345 \pm 0.0730^{c}$ & $0.6026 \pm 0.0780$ & .002 \\
\hline Inferior temporal gyrus & $0.4969 \pm 0.0659$ & $0.4852 \pm 0.0914$ & $0.5639 \pm 0.0674$ & .001 \\
\hline Anterior corona radiata & $0.5000 \pm 0.0691^{b}$ & $0.4985 \pm 0.0676^{b}$ & $0.0580 \pm 0.0739$ & $<.001$ \\
\hline Posterior corona radiata & $0.6537 \pm 0.0988$ & $0.6484 \pm 0.0916$ & $0.7148 \pm 0.0837$ & .02 \\
\hline Auditory radiation & $0.5950 \pm 0.0848$ & $0.5948 \pm 0.0860$ & $0.6607 \pm 0.0819$ & .008 \\
\hline Brodmann area 41 & \multicolumn{2}{|c|}{$0.5515 \pm 0.1041^{c}$} & $0.6303 \pm 0.0850$ & .002 \\
\hline Brodmann area 42 & \multicolumn{2}{|c|}{$0.4792 \pm 0.0756$} & $0.5421 \pm 0.0860$ & .004 \\
\hline
\end{tabular}

project to the MGB in the thalamus. Finally, the acoustic radiation from the MGB transmits the auditory information to the temporal cortex through the internal capsule. ${ }^{17}$

Most studies examining white matter microstructure in sensorineural hearing loss have focused on long-term patients, and the auditory cortex, inferior colliculus, and lateral lemniscus are the most widely studied regions using DTI. ${ }^{10}$ Some DTI studies have focused on only the lateral lemniscus and inferior colliculus because the 2 sides are more distinguishable along the auditory pathway. ${ }^{8}$ In these regions, the auditory nerve fibers are predominantly oriented vertically, while other regions including the cochlear nuclei, superior olivary body, and MGB contain longitudinal, transverse, and oblique fibers, leading to poor spatial resolution and signal-to-noise ratio. ${ }^{8,17,18}$ By contrast, DSI was reported to have the highest sensitivity for detecting crossing fibers compared with DTI and diffusional kurtosis imaging. ${ }^{19}$ Therefore, in this study, we chose DSI to detect microstructural abnormalities along the central auditory pathway and to assess the correlations of clinical outcomes with DSI parameters.

An observed decrease in FA is likely attributed to axonal loss and/or demyelination. ${ }^{18}$ GFA, as the SD of diffusion directions within a voxel, is the parameter of DSI simulation of FA deriving from DTI. ${ }^{12}$ QA is an anisotropy index similar to FA, but it is calculated for each orientation-distribution function peak in each voxel. $^{20}$ The decrease of QA and GFA both can reflect the damage to white matter, just like FA.

A major finding of this study was the prognostic value of GFA in the ipsilateral MGB. In addition, the QA value decreased on the contralateral side of the MGB. A relationship between QA reduction of the contralateral MGB and the severity of hearing loss was found in our previous research. ${ }^{21}$ The MGB plays a central role in auditory processing. It is the efferent and afferent tracts to the primary auditory cortex, responsible for the complex perception of sounds. ${ }^{22}$ Huang et $\mathrm{al}^{23}$ also reported that FA in the MGB is a valuable predictive biomarker of cochlear implantation outcome. This report confirmed that MGB may have predictive value in the process of hearing rehabilitation.

Given that $70 \%-80 \%$ of the fibers cross to the contralateral side, and only $20 \%-30 \%$, to the ipsilateral side, how does GFA of the ipsilateral MGB affect prognosis? In the improvement group, GFA of the ipsilateral MGB was significantly higher than that of the contralateral side of the same patient, while there were no differences between the ipsilateral and contralateral sides of each patient in the nonimprovement group. These data suggest that the ipsilateral side of nerve fiber integrity was better in patients with good prognosis. Langers et $\mathrm{al}^{24}$ found that the stimulation to deaf ears of patients with unilateral hearing loss can cause weak responses in the MGB, and these responses were strongest ipsilateral to the deaf side. In contrast, the response of the MGB to stimulation was dominantly contralateral in the subjects with normal hearing. Thus, speculatively, ipsilateral compensation may have occurred because of the contralateral injury. The better ipsilateral fiber integrity is conducive to the transmission of nerve impulses, which may improve the prognosis. Further studies are required to confirm the mechanism of hearing recovery in patients with unilateral ISSHL. Yang et $\mathrm{al}^{25}$ also reported that the decreased hearing level of the opposite ear was a poor prognostic factor in elderly patients with unilateral sensorineural hearing loss. This effect of the opposite ear on prognosis may also explain why better fiber integrity of the hearing loss on the ipsilateral side was associated with better prognosis. This finding is because $70 \%-$ $80 \%$ of the fibers of the opposite ear cross over to the hearing loss on the ipsilateral side.

Prognostic factors for ISSHL have been reported in several studies, including age, degree of hearing loss, shape of the audiogram, duration between the onset of hearing loss and treatment, and complications such as hypertension and hyperlipidemia, of which the severity of the initial hearing loss is considered the most important. ${ }^{26}$ By contrast, we found no differences in the above indices between patients with different hearing outcomes. Only 6 (12.5\%) cases of moderate hearing loss were observed in the present study 

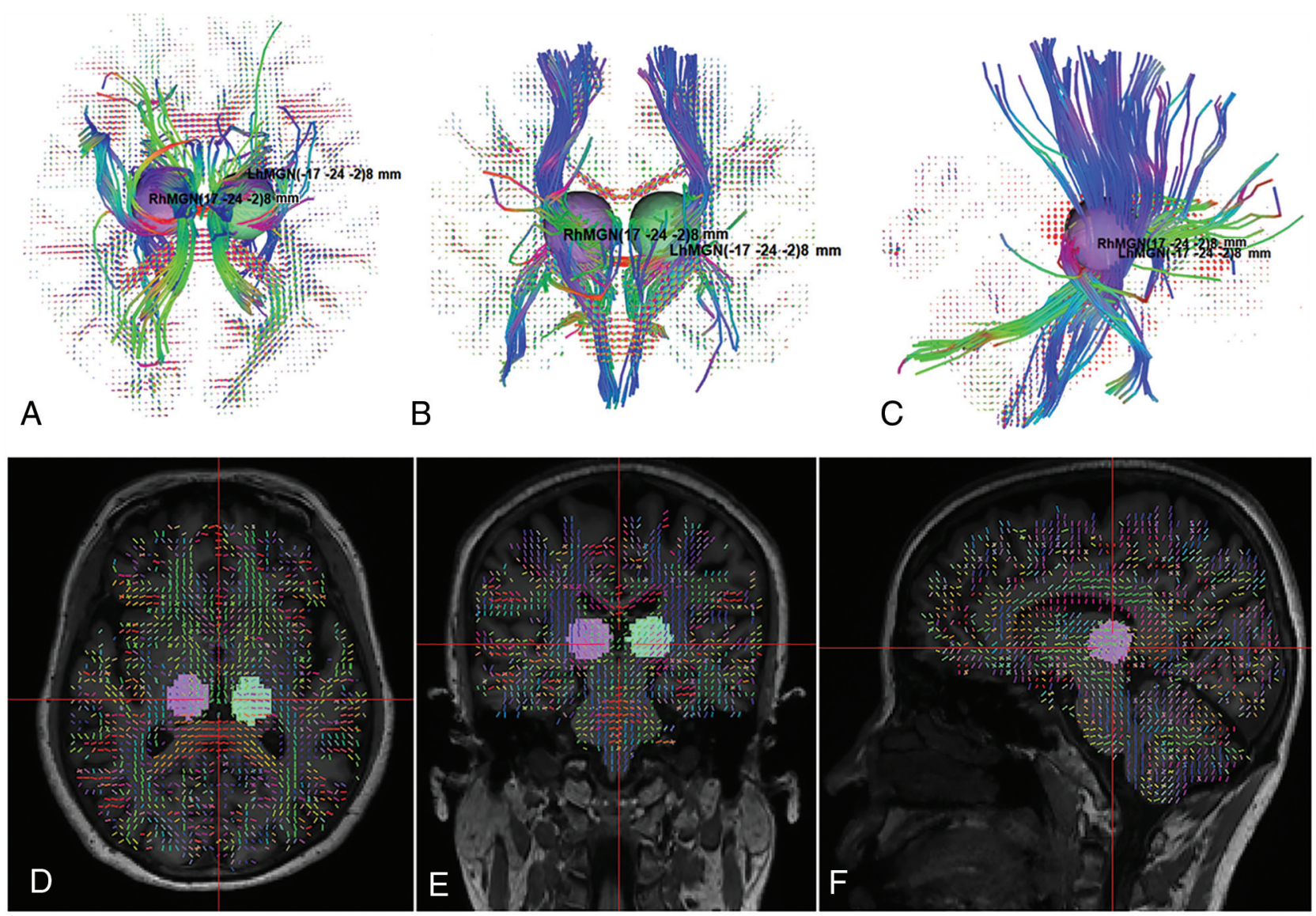

FIG 1. Fiber tractography of the MGB from diffusion spectrum imaging: $A$, Axial. $B$, Coronal. $C$, Sagittal. ROIs on the QA map: $D$, Axial. $E$, Coronal. F, Sagittal. RhMGN indicates Right MGB; LhMGN, Left MGB.

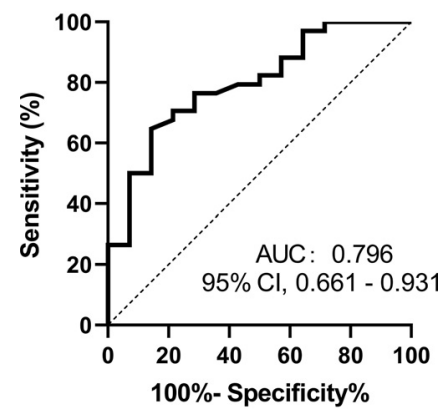

FIG 2. The receiver operating characteristic curves of GFA in the ipsilateral MGB. AUC indicates area under the curve.

(less than the other 3 severities), which may partially explain the absence of effects of hearing loss on prognosis.

This study also showed a decrease of QA value in the lateral lemniscus. However, differing from some previous studies, this study failed to find changes in the inferior colliculus. For example, $\mathrm{Wu}$ et $\mathrm{al}^{18}$ reported significant differences of $\mathrm{FA}$ in both the lateral lemniscus and inferior colliculus of patients with sensorineural hearing loss, while Lin et $\mathrm{al}^{17}$ reported an inverse relationship between the severity of hearing impairment and FA values in those 2 sites. Lee et $\mathrm{al}^{27}$ found greater differences in the inferior colliculus (the site of convergence for input from multiple lower auditory nuclei) compared with the lateral colliculus, suggesting increased sensitivity of the inferior colliculus to injury. Furthermore, Chang et $\mathrm{al}^{9}$ thought that the inferior colliculus was the most common region of the central auditory pathway showing a reduced FA. Nevertheless, in that study, FA of the inferior colliculus decreased in all 8 patients with bilateral hearing loss, but in only 1 of 2 patients with unilateral hearing loss. By contrast, in a study focused on patients with hearing loss with chronic tinnitus, Husain et $\mathrm{al}^{28}$ found no change in FA in those 2 sites. Most interesting, in a DTI study examining the effect of disease duration on the central auditory nerve fibers in patients with ISSHL, there was no change in the DTI index of those 2 sites with a duration of $<1$ week, while significant changes were found in patients with a duration of $>2$ years. ${ }^{8}$ Thus, we speculated that the duration of hearing loss may impact the structural changes in the auditory pathways because of compensation. Overall, these data suggest that unilateral or bilateral hearing loss and different durations may explain, at least in part, our contrasting findings in the inferior colliculus.

Consistent with our results, Shang et $\mathrm{al}^{29}$ found a reduction of DTI parameters in the anterior and posterior limbs of the internal capsule, the middle temporal gyrus, and the anterior corona radiata in unilateral deafness. They thought axonal demyelination was the main mechanism of structural change. Lexical/semantic processing requires input from the middle temporal gyrus. In addition to our finding of bilateral white matter damage, Fan et $\mathrm{al}^{30}$ found a decrease of gray matter in 
the contralateral middle temporal gyrus of patients with hearing loss. Husain et $\mathrm{al}^{28}$ also found decreased FA values in the internal capsule. The internal capsule is important to auditory function because it contains most of the afferent auditory fibers that enter the cortical area. Most auditory fibers are located in the posterior limb of the internal capsule. The anterior limb of the internal capsule is related to cognitive function because it connects the thalamus and prefrontal cortex, conveying cognition fibers. ${ }^{31}$ A study of patients with tinnitus also showed that the anterior corona radiation is one of the most changed areas in white matter. ${ }^{32}$ These above results indicate that we need to pay more attention to cognitive function and tinnitus in future research of ISSHL.

Finally, this study also found that QA decreased in Brodmann Area 41. Brodmann Area 41 is the primary auditory area. The results suggested that the short-term course of disease may already have affected the structural changes in the auditory area. However, changes in this area have not been reported in previous DTI studies in patients with ISSHL; these changes need further research and verification.

There were several limitations in our study. The patients were enrolled from a single institution, and the data were analyzed retrospectively. Furthermore, all patients received the same treatment strategy. Thus, we were unable to compare the effects of different treatment strategies on fiber integrity.

\section{CONCLUSIONS}

Our data suggest that DSI can detect abnormalities of white matter microstructure along the central auditory pathway in patients with unilateral ISSHL, and GFA in the ipsilateral MGB may help to predict recovery outcomes.

\section{ACKNOWLEDGMENTS}

The authors thank the staff from the Department of Otolaryngology at Beijing Chaoyang Hospital.

Disclosures: Yi Zhang—RELATED: Grant: Beijing Municipal Commission of Science and Technology*; Fees for Participation in Review Activities Such as DataMonitoring Boards, Statistical Analysis, End-Point Committees, and the Like: Beijing Municipal Commission of Science and Technology.* Zihao Zhang-RELATED: Grant: Beijing Municipal Commission of Science and Technology*; Fees for Participation in Review Activities Such as Data-Monitoring Boards, Statistical Analysis, End-Point Committees, and the Like: Beijing Municipal Commission of Science and Technology.* Xiaojiao Guan—RELATED: Grant: Beijing Municipal Commission of Science and Technology*; Fees for Participation in Review Activities Such as DataMonitoring Boards, Statistical Analysis, End-Point Committees, and the Like: Beijing Municipal Commission of Science and Technology. ${ }^{*}$ Yuelei Lyu—RELATED: Grant: Beijing Chaoyang Hospital*; Consulting Fee Or Honorarium: Beijing Chaoyang Hospital*; Support for Travel to Meetings for the Study or Other Purposes: Beijing Chaoyang Hospital*; Fees for Participation in Review Activities Such as DataMonitoring Boards, Statistical Analysis, End-Point Committees, and the Like: Beijing Chaoyang Hospital.* Jing Yang-RELATED: Grant: Beijing Municipal Commission of Science and Technology*; Fees for Participation in Review Activities Such as DataMonitoring Boards, Statistical Analysis, End-Point Committees, and the Like: Beijing Municipal Commission of Science and Technology.* Tao Jiang-RELATED: Grant: Beijing Municipal Commission of Science and Technology*; Fees for Participation in Review Activities Such as Data-Monitoring Boards, Statistical Analysis, End-Point Committees, and the Like: Beijing Municipal Commission of Science and Technology.* Xiuqin Jia—RELATED: Grant: Beijing Municipal Commission of Science and Technology*; Fees for Participation in Review Activities Such as DataMonitoring Boards, Statistical Analysis, End-Point Committees, and the Like: Beijing Municipal Commission of Science and Technology. * ${ }^{*}$ Money paid to the institution.

\section{REFERENCES}

1. Xie Y, Orabi NA, Zwolan TA, et al. Outcomes of unilateral idiopathic sudden sensorineural hearing loss: two decades of experience. Laryngoscope Investig Otolaryngol 2019;4:693-702 CrossRef Medline

2. Ahmadzai N, Kilty S, Cheng W, et al. A systematic review and network meta-analysis of existing pharmacologic therapies in patients with idiopathic sudden sensorineural hearing loss. PLoS One 2019;14:e022171 CrossRef Medline

3. Chandrasekhar SS, Tsai Do BS, Schwartz SR, et al. Clinical practice guideline: sudden hearing loss (update). Otolaryngol Head Neck Surg 2019;161:S1-45 CrossRef Medline

4. Jalali MM, Nasimidoust Azgomi M. Metabolic syndrome components and sudden sensorineural hearing loss: a case-control study. Eur Arch Otorhinolaryngol 2020;277:1023-29 CrossRef Medline

5. Ciorba A, Bianchini C, Crema L, et al. White matter lesions and sudden sensorineural hearing loss. J Clin Neurosci 2019;65:6-10 CrossRef Medline

6. Fusconi M, Attanasio G, Capitani F, et al. Is there a relation between sudden sensorineural hearing loss and white matter lesions. Eur Arch Otorhinolaryngol 2019;276:3043-49 CrossRef Medline

7. Dicuonzo F, Purciariello S, De Marco A, et al. MR evaluation of encephalic leukoaraiosis in sudden sensorineural hearing loss (SSNHL) patients. Neurol Sci 2019;40:357-62 CrossRef Medline

8. Zhu K, He Y, Hou J, et al. Diffusion tensor imaging study of central auditory pathway in patients with acquired sensorineural hearing loss. J of Audiol and Speech Pathol 2015;23:143-46 CrossRef

9. Chang Y, Lee SH, Lee YJ, et al. Auditory neural pathway evaluation on sensorineural hearing loss using diffusion tensor imaging. Neuroreport 2004;15:1699-703 CrossRef Medline

10. Tarabichi O, Kozin ED, Kanumuri VV, et al. Diffusion tensor imaging of central auditory pathways in patients with sensorineural hearing loss: a systematic review. Otolaryngol Head Neck Surg 2018;158:432-42 CrossRef Medline

11. Yeh FC, Wedeen VJ, Tseng WY. Generalized q-sampling imaging. IEEE Trans Med Imaging 2010;29:1626-35 CrossRef Medline

12. Hodgson K, Adluru G, Richards LG, et al. Predicting motor outcomes in stroke patients using diffusion spectrum MRI microstructural measures. Front Neurol 2019;10:72 CrossRef Medline

13. Editorial Board of Chinese Journal of Otorhinolaryngology Head and Neck Surgery; Society of Otorhinolaryngology Head and Neck Surgery, Chinese Medical Association. Guideline of diagnosis and treatment of sudden deafness (2015) [in Chinese]. Zhonghua Er Bi Yan Hou Tou Jing Wai Ke Za Zhi 2015;50:443-47 Medline

14. Wedeen VJ, Hagmann P, Tseng WY, et al. Mapping complex tissue architecture with diffusion spectrum magnetic resonance imaging. Magn Reson Med 2005;54:1377-86 CrossRef Medline

15. Fernández-Miranda JC, Wang Y, Pathak S, et al. Asymmetry, connectivity, and segmentation of the arcuate fascicle in the human brain. Brain Struct Funct 2015;220:1665-80 CrossRef Medline

16. Fernandez-Miranda JC, Pathak S, Engh J, et al. High-definition fiber tractography of the human brain: neuroanatomical validation and neurosurgical applications. Neurosurgery 2012;71:430-53 CrossRef Medline

17. Lin $\mathrm{Y}, \mathrm{Wang} \mathrm{J}, \mathrm{Wu} \mathrm{C}$, et al. Diffusion tensor imaging of the auditory pathway in sensorineural hearing loss: changes in radial diffusivity and diffusion anisotropy. J Magn Reson Imaging 2008;28:598603 CrossRef Medline

18. Wu CM, Ng SH, Liu TC. Diffusion tensor imaging of the subcortical auditory tract in subjects with long-term unilateral sensorineural hearing loss. Audiol Neurootol 2009;14:248-53 CrossRef Medline

19. Glenn GR, Kuo LW, Chao YP, et al. Mapping the orientation of white matter fiber bundles: a comparative study of diffusion tensor imaging, diffusional kurtosis imaging, and diffusion spectrum imaging. AJNR Am J Neuroradiol 2016;37:1216-22 CrossRef Medline

20. Yeh FC, Verstynen TD, Wang Y, et al. Deterministic diffusion fiber tracking improved by quantitative anisotropy. PLoS One 2013;8: e80713 CrossRef Medline 
21. Zhang Z, Jia X, Guan X, et al. White matter abnormalities of auditory neural pathway in sudden sensorineural hearing loss using diffusion spectrum imaging: different findings from tinnitus. Front Neurosci 2020;14:200 CrossRef Medline

22. Bartlett EL. The organization and physiology of the auditory thalamus and its role in processing acoustic features important for speech perception. Brain Lang 2013;126:29-48 CrossRef Medline

23. Huang L, Zheng W, Wu C, et al. Diffusion tensor imaging of the auditory neural pathway for clinical outcome of cochlear implantation in pediatric congenital sensorineural hearing loss patients. PLoS One 2015;10:e0140643 CrossRef Medline

24. Langers DR, van Dijk P, Backes WH. Lateralization, connectivity and plasticity in the human central auditory system. Neuroimage 2005;28:490-99 CrossRef Medline

25. Huafeng Y, Hongqin W, Wenna Z, Yuan L, Peng X. Clinical characteristics and prognosis of elderly patients with idiopathic sudden sensorineural hearing loss. Acta Otolaryngol 2019;139:866-69 CrossRef Medline

26. Lee HY, Kim DK, Park YH, et al. Prognostic factors for profound sudden idiopathic sensorineural hearing loss: a multicenter retrospective study. Eur Arch Otorhinolaryngol 2017;274:143-49 CrossRef Medline
27. Lee SH, Chang Y, Lee JE, et al. The values of diffusion tensor imaging and functional MRI in evaluating profound sensorineural hearing loss. Cochlear Implants Int 2004;5(Suppl 1):149-52 CrossRef Medline

28. Husain FT, Medina RE, Davis CW, et al. Neuroanatomical changes due to hearing loss and chronic tinnitus: a combined VBM and DTI study. Brain Res 2011;1369:74-88 CrossRef Medline

29. Shang Y, Hinkley LB, Cai C, et al. Functional and structural brain plasticity in adult onset single-sided deafness. Front Hum Neurosci 2018;12:474 CrossRef Medline

30. Fan W, Zhang W, Li J, et al. Altered contralateral auditory cortical morphology in unilateral sudden sensorineural hearing loss. Otol Neurotol 2015;36:1622-27 CrossRef Medline

31. Yin B, Li DD, Huang $\mathrm{H}$, et al. Longitudinal changes in diffusion tensor imaging following mild traumatic brain injury and correlation with outcome. Front Neural Circuits 2019;13:28 CrossRef Medline

32. Yoo HB, De Ridder D, Vanneste $S$. White matter changes in tinnitus: is it all age and hearing loss. Brain Connect 2016;6:84-93 CrossRef Medline 